\title{
Safety of users in road evacuation: general methodology and main results
}

\author{
F. Russo \& A. Vitetta \\ Department of Computer Science, Mathematics, \\ Electronics and Transportation, \\ Mediterranea University of Reggio Calabria, Italy
}

\begin{abstract}
In this paper we present the main results of the SICURO project. The aims of the project are:

- to calibrate, validate and test models and procedures to assess the effects of action to reduce risk in terms of exposure based on general real evacuations;

- to construct a prototype laboratory system of models for public administration where models and procedures are implemented;

- $\quad$ to provide public administration with guidelines for planning and managing evacuation in an urban system under emergency conditions.
\end{abstract}

We present the project, the methodology and the main general results obtained from experimentation. A detailed description is reported in the other paper of the session.

Keywords: risk analysis, transportation models.

\section{Introduction}

In this paper we present the main results obtained from the SICURO project within a unifying approach for simulating and designing a transportation system under conditions of hazard.

Safety and security concern threats generated by very different factors and which, in turn, generate emergency conditions, such as the 9/11, Madrid and London attacks, the Asian tsunami, and hurricane Katrina, all occurred in just the last six years.

The development of models for emergency conditions in transportation systems has not received much attention in the literature. To the authors' 
knowledge the main findings in this area are limited to only a few public research centres (Los Alamos National Laboratory, [1]; University of Maryland, [2]; Mediterranea University of Reggio Calabria, [3]) and private companies (KLD, [4]). In the literature only specific aspects are treated concerning largescale emergencies when a nuclear threat occurs, in urban systems when general hazards occur and for evacuating buildings or ships during fires. Models and algorithms specified and calibrated in ordinary conditions [5-8] cannot be directly applied in emergency conditions under the usual hypothesis considered.

The model for evacuation can be applied in the context of the "what if" (or simulation) or "what to" (or optimization) approach. The what if (or simulation) approach consists in defining some scenarios and finding the system configurations consistent with the supply/demand interaction models. The what to (or design) approach consists in defining some objectives and finding the system configurations as the optimum of an objective function.

The process for risk analysis can be divided into two main approaches [10]:

- $\quad$ risk assessment; this consists in estimating the probability of a hazard and the consequence severity, in relation to possible threats (simulation model);

- risk management; this entails analysing the possible options for risk reduction and designing and applying mitigation measures (design model).

This paper is developed with the following main objectives:

(a) to describe the SICURO project;

(b) to formalize the risk problem and a system of models for evacuation design and simulation;

(c) to experiment, specify, calibrate, validate and apply the model in a real system.

In relation to the proposed objectives in this paper the following are reported:

(a) in section 2 the general structure of the SICURO project;

(b) in section 3 a general framework with specific methods and models to analyze urban transportation system performances in emergency conditions when exogenous phenomena occur and for the specification of the risk function;

(c) in section 4 the main general results obtained from the experimentation are reported. The title of the specific papers and the conclusions are reported in section 5 .

\section{The project}

We present the results relative to the SICURO project within the framework of the EU-funded 2000-06 Regional Operative Plan of the Calabria Region).

The aims of the SICURO project are:

(i) to calibrate, validate and test models and procedures to assess the effects of action to reduce risk in terms of exposure based on general real evacuations;

(ii) to construct a prototype system of models for public administration where models and procedures are implemented;

(iii) to provide public administration with guidelines for planning and managing evacuation in an urban system under emergency conditions. 
Actions (i) concern specification and calibration of the system of models for transportation system analysis in an urban area in emergency conditions and validation of the general procedure for risk reduction in terms of exposure. The above operations are preceded by an extended experimentation phase in order to measure evacuation characteristics in an urban area after an emergency simulated event. Experimental data are provided from official sources and from field surveys.

Actions (ii) concern the design and development of a system of models for planning and managing an urban system in emergency conditions. The models constitute a planning tool for reducing the consequences of an emergency event, allowing the design of transport supply and management of transport demand in emergency conditions. They are calibrated and validated through an experimentation conducted in the town of Melito Porto Salvo (Italy).

Actions (iii) aim to define guidelines for public administrations, agencies and operators, for planning and managing an urban system in emergency conditions.

In order to achieve its aims the project has the following structure.

1) State-of-the-art methodology to define risk and reduce exposure in an urban area resulting from disastrous events.

2) General formulation and definition of exposure.

3) Construction of theoretical models and general procedures to evaluate exposure in emergency conditions considering

a. demand models;

b. supply and supply-demand interaction models for users;

c. simulation of refuge areas for users;

d. design of path choice models for emergency vehicles;

e. pedestrian outflow models in a building;

f. planning process and guidelines.

4) Real experimentation in the urban area of Melito Porto Salvo in the province of Reggio Calabria (Italy); the aim of the experiment is to measure evacuation characteristics in an urban area after a disastrous event; people present in the area are notified of the event and are asked to reach preestablished refuge areas. Two types of experimentation are developed:

a. pre-test, where an area with only public offices and one school is evacuated;

b. test, where all the people in the area are evacuated.

\section{Model}

Drawing up an evacuation plan for an urban area requires a study of issues concerning land use and risk reduction. The complete procedure for developing an evacuation plan can be subdivided into the following variously connected phases:

- study of the infrastructures and land use and definition of objectives and constraints;

- generation of scenarios for supply and demand; 
- $\quad$ probability and vulnerability evaluation for the exogenous risk scenario;

- model for supply, demand and supply/demand interaction;

- evaluation of exposure and risk acceptance.

In Figure 1 the proposed system of models and the relative functional connections are represented, which may be used for testing evacuation plans by means of quantitative methods.

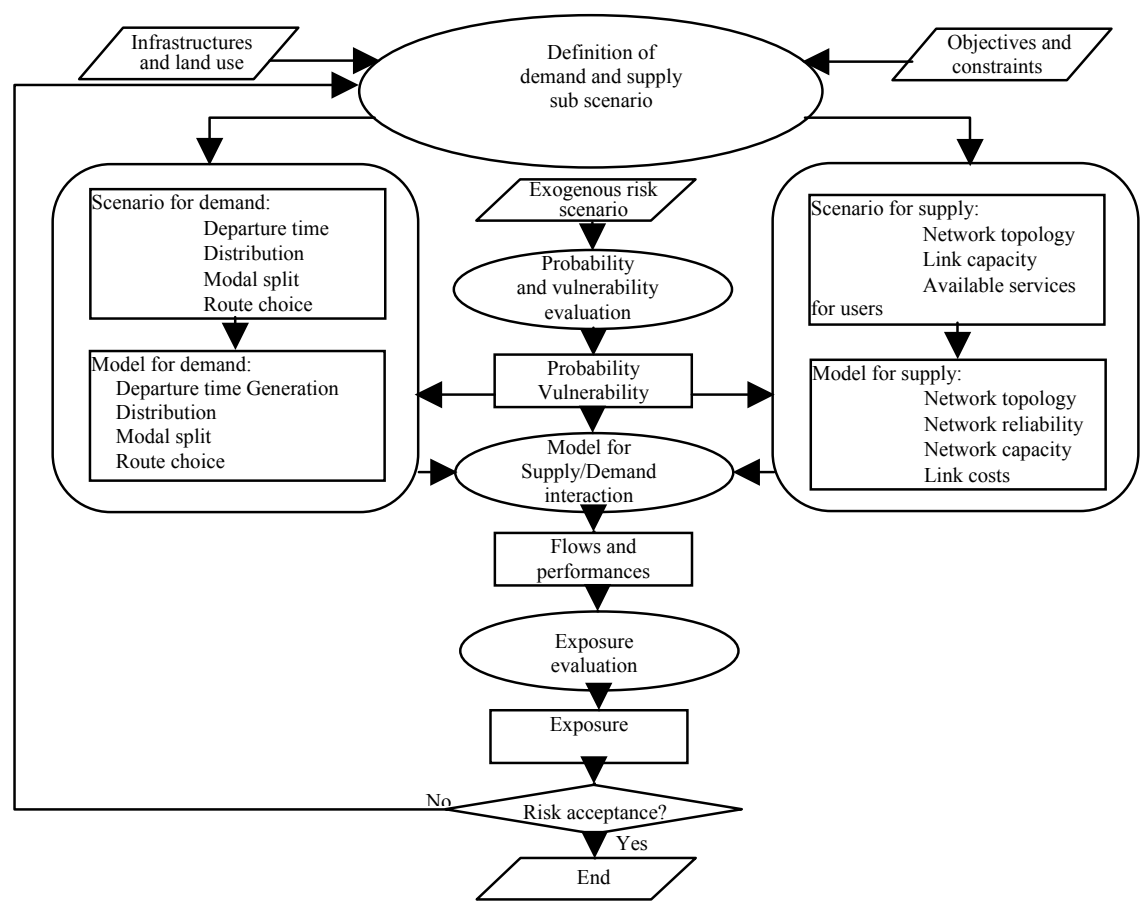

Figure 1: The procedure for the evacuation plan and relevant links.

Risk can be defined as a cardinal measure of potential economic loss, human injury or environmental damage in terms of both incident probability and the magnitude of the loss, injury or damage. Risk can be expressed as the product between the probability that an emergency event occurs and the magnitude that is a measure of the effect of the event. The magnitude can be expressed as the product between system vulnerability and system exposure. Exposure can be defined as the equivalent homogeneous weighted value of people, goods and infrastructures affected during and after the event.

Starting from the definition of risk by which it depends on the probability $\mathrm{P}$ (or the frequency) that the threat occurs and on the magnitude $\mathrm{M}$ of the loss, injury, or damage, in a simplified version societal risk $\mathrm{R}$ can be defined as ([9]):

$$
\mathrm{R}=\mathrm{P} \mathrm{M}
$$


Eq. (1) can be also written in the form:

$$
\mathrm{R}=\mathrm{P} \text { V N }
$$

where the magnitude $\mathrm{M}$ is defined as $\mathrm{M}=\mathrm{VN}$, with $\mathrm{V}$ representing vulnerability and $\mathrm{N}$ exposure.

Considering eq. (1) two types of measure for risk reduction may be defined:

- $\quad$ prevention, which consists in reducing the level of $\mathrm{P}$;

- $\quad$ rotection, which consists in reducing the level of $\mathrm{M}$.

The magnitude $(\mathrm{M}=\mathrm{V} \mathrm{N})$ can be reduced with two classes of measure:

- resistance, which consists in reducing the level of $\mathrm{V}$;

- evacuation, which consists in reducing the level of $\mathrm{N}$.

Evacuation consists in reducing the number of users and goods that can experience adverse effects when hazardous emergencies occur. Reduction in exposure is discussed in this paper.

In this paper a generalized formulation is considered for the risk assessment that goes beyond the traditional formulation where vulnerability and exposure are considered constant throughout the area studied. More details may be found in [11].

Risk can be divided into three components: probability, vulnerability and exposure. Each component can be characterized by one or more of the following variables: an intensity level $x$, a point in space $y$, a time $t$.

Having defined an emergency threat $E$ (for instance a radiation leakage in a nuclear power station) in an area Y (land around the power station), threat E may occur in $\mathrm{Y}$ with an intensity level in the range $\mathrm{L}_{\mathrm{E}}$ (for example the intensity of radiation emissions between two prefixed values), in a certain time slice (for example in the subsequent 2 years).

The time slice $\Delta$ (Figure 2 ) is the period over which the analysis is developed. It varies according to the scenario: several years for long term, some months or days for short term, some days or hours or minutes for now-casting. Within the time slice $\Delta, 4$ main intervals have to be defined $\left(\Delta_{0} \subset \Delta ; \Delta_{1} \subset \Delta ; \Delta_{2} \subset \Delta, \Delta_{3} \subset\right.$ $\Delta)$ :

- $\Delta_{0}=\left(\mathrm{t}_{0}, \mathrm{t}_{1}\right]$ between the times

$\mathrm{t}_{0}$, the time when the study of the evacuation plan is started;

$\mathrm{t}_{1}$, the time when the hazardous event is known to happen or supposed forecasted;

- $\Delta_{1}=\left(\mathrm{t}_{1}, \mathrm{t}_{2}\right]$ between the times $\mathrm{t}_{2}$ and $\mathrm{t}_{3}$, the time when the threat occurs and becomes a dangerous event and starts its effects;

- $\Delta_{2}=\left(t_{2}, t_{3}\right]$ between times $t_{2}$ and $t_{3}$, the time when the final effect occurs and people cannot be rescued;

- $\Delta_{3}=\left(t_{3}, t_{4}\right]$ between times $t_{3}$ and $t_{4}$, the time when the hazardous event ceases its effect on the population.

After instant $t_{4}$ all the traditional mitigation actions of civil and military forces start.

The plan is developed within time slice $\Delta$ but before time $\mathrm{t}_{1}$ (interval $\Delta_{0}$ ). Risk assessment consists in evaluating the possible threats and their relative evolution in the possible intervals $\Delta_{1}, \Delta_{2}$ and $\Delta_{3}$ within $\Delta$. In most cases the interval $\Delta_{0}$ is 
greater than the other intervals; for some threats some of the intervals $\Delta_{1}, \Delta_{2}$ and $\Delta_{3}$ are with zero extension. For example, if we have to evaluate the risk for seismic threats, the interval $\Delta_{0}$ is evaluated in the order of 100 years. The dimension of the intervals $\Delta_{1}$ is zero, and $\Delta_{2}$ and $\Delta_{3}$ are non-zero. If we have to evaluate the risk of tsunamis, the interval $\Delta_{0}$ is evaluated in the order of a decade. The size of the intervals $\Delta_{1}$ is about one hour, depending on the distance of the source.

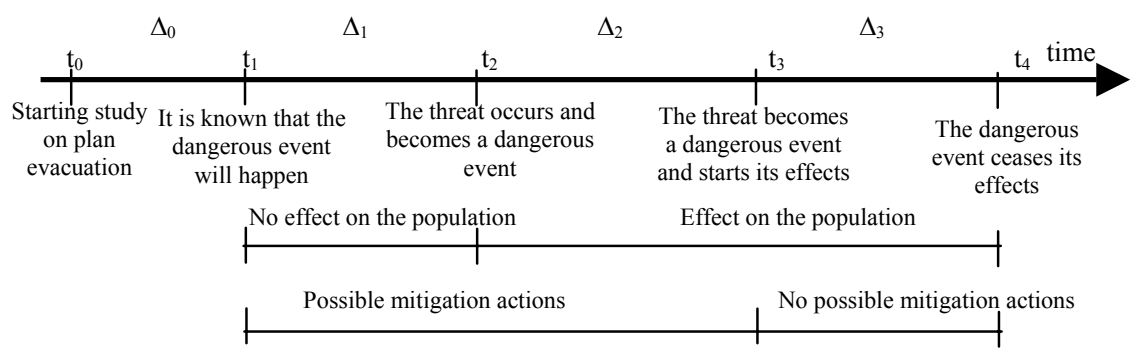

Figure 2: Time subdivision relative to the event's occurrence.

For each threat a probability function $p_{\Delta}(\mathrm{x}, \mathrm{y})$ can be defined where $\mathrm{x}$ and $\mathrm{y}$ are respectively the variables for the intensity level in the range $L_{E}$, the area $Y$ and the time slice $\Delta$. In relation to the probability function $p$ defined, $\mathrm{P}$ can be interpreted as the average value of the function $p_{\Delta}$ with respect to $\mathrm{x}$ and $\mathrm{y}$ in the time slice $\Delta$. With this interpretation, the following relation can be defined:

$$
\mathrm{P}=\int_{\mathrm{x} \in \mathrm{L}_{\mathrm{E}}} \int_{\mathrm{y} \in \mathrm{Y}} p_{\Delta}(\mathrm{x}, \mathrm{y}) \mathrm{dy} \mathrm{dx} /\left(\int_{\mathrm{x} \in \mathrm{L}_{\mathrm{E}}} \int_{\mathrm{y} \in \mathrm{Y}} \mathrm{dy} \mathrm{dx}\right)
$$

The level of magnitude that produces a threat $\mathrm{E}$ with intensity level $\mathrm{x}$ at point $\mathrm{y}$ of $\mathrm{Y}$ is $\mathrm{M}(\mathrm{x}, \mathrm{y}, \mathrm{z})$ given by the product of:

$$
\mathrm{M}(\mathrm{x}, \mathrm{y}, \mathrm{z})=\mathrm{V}(\mathrm{x}, \mathrm{y}, \mathrm{z}) \mathrm{N}_{\mathrm{t}_{3}}(\mathrm{y})
$$

where

- vulnerability $\mathrm{V}(\mathrm{x}, \mathrm{y}, \mathrm{z})$ is the capacity of infrastructures (building, road, bridge, ....) at point $\mathrm{y}$ of not withstanding threat $\mathrm{E}$ with intensity level $\mathrm{x}$, during the time intervals $\mathrm{z}$ belonging to $\Delta_{1}, \Delta_{2}$ and $\Delta_{3}$;

- exposure $\mathrm{N}_{\mathrm{t}_{3}}(\mathrm{y})$ is the equivalent homogeneous weighted value of people, goods and infrastructures at point $y$ of $Y$ affected in time $t_{3}$.

With the given definitions and notations (3) and (4), assessments can be made with two indexes:

- for individual risk

$$
\left.\mathrm{R}_{\mathrm{L}_{\mathrm{E}}, \mathrm{Y}, \Delta}^{\mathrm{i}}(\mathrm{y})=\int_{\mathrm{x} \in \mathrm{L}_{\mathrm{E}}} \int_{\mathrm{z} \in \Delta_{1} \cup \Delta_{2} \cup \Delta_{3}} \mathrm{M}(\mathrm{x}, \mathrm{y}, \mathrm{z}) \mathrm{p}_{\Delta}(\mathrm{x}, \mathrm{y}) \mathrm{dz} d \mathrm{dx} /\left[\int_{\mathrm{z} \in \Delta_{1} \cup \Delta_{2} \cup \Delta_{3}} \mathrm{dz} \int_{\mathrm{x} \in \mathrm{L}_{\mathrm{E}}} \mathrm{dx}\right)\right]
$$

- for societal risk

$$
\begin{aligned}
\mathrm{R}_{\mathrm{L}_{\mathrm{E}}, \mathrm{Y}, \Delta} & =\int_{\mathrm{y} \in \mathrm{Y}} \mathrm{R}_{\mathrm{L}_{\mathrm{E}}, \mathrm{Y}, \Delta}^{\mathrm{i}}(\mathrm{y}) \mathrm{dy}= \\
\quad & \int_{\mathrm{y} \in \mathrm{Y}} \int_{\mathrm{x} \in \mathrm{L}_{\mathrm{E}}} \int_{\mathrm{z} \in \Delta_{1} \cup \Delta_{2} \cup \Delta_{3}} \mathrm{M}(\mathrm{x}, \mathrm{y}, \mathrm{z}) \mathrm{p}_{\Delta}(\mathrm{x}, \mathrm{y}) \mathrm{dz} d \mathrm{x} d \mathrm{~d} /\left(\int_{\mathrm{z} \in \Delta_{1} \cup \Delta_{2} \cup \Delta_{3}} \mathrm{dz} \int_{\mathrm{x} \in \mathrm{L}_{\mathrm{E}}} \mathrm{dx}\right)
\end{aligned}
$$


In relation to the time instant defined in figure 2 the societal risk can have different values in instants $t_{1}$ and $t_{3}$ if evacuation action is well designed. If no evacuation is activated, the two values are the same; if evacuation action is implemented, in relation to the efficiency of the evacuation and the length of the time intervals $\Delta_{1} \cup \Delta_{2}$, the risk for the population in instant $t_{3}$ could be zero.

In the hypothesis of vulnerability $V(\mathrm{x}, \mathrm{y}, \mathrm{z})$, constant with respect to $\mathrm{Y}$, in the time interval $\Delta_{1} \cup \Delta_{2} \cup \Delta_{3}$ and in the range $\mathrm{L}_{\mathrm{E}}$, and equal to $\mathrm{V}$ and exposure $N_{\mathrm{t}_{3}}(\mathrm{y})$, constant in $\mathrm{Y}$ and equal to $\mathrm{N}$, societal risk assumes the simple form:

$$
\mathrm{R}_{\mathrm{L}_{\mathrm{E}}, \mathrm{Y}, \Delta}=\mathrm{P} \text { V N }
$$

\section{Experimentation}

The SICURO project comprises an extended experimentation phase of population evacuation from an urban area, in order to construct a complete database which is required to specify and calibrate the system of models for transportation system analysis in an urban area in emergency conditions and validate the general procedure for risk reduction in terms of exposure. The urban zone considered is Melito Porto Salvo (Italy), occupying an area of $42,990 \mathrm{~m}^{2}$.

The data are recorded for laboratory analysis. Our experiment requires that socioeconomic information (population, number employed, public buildings, schools, etc.) and transport supply characteristics (infrastructures, etc.) be measured before and during experimentation. Information can be found in official sources and specific surveys with manual/automatic tools and 30 video cameras. From these surveys we can obtain variables for calibrating and validating the models.

From the analysis of Figure 1 the following activities can be extracted:

- network construction for pedestrian, private vehicles and public vehicles, design of safe centres and disabled services from the supply scenario;

- specification, calibration and validation of demand models from the demand scenario;

- pedestrian and private vehicle simulation, public vehicles, disabled services and safe centre design from the supply-demand interaction model.

In accordance with the SICURO project, the results are divided into six strictly connected tasks:

- Demand models;

- Supply and supply-demand interaction models for users;

- Simulation of refuge areas for users;

- Design of path choice models for emergency vehicles;

- Pedestrian outflow models in a building;

- Planning process and guidelines.

In the town of Melito Porto Salvo the area selected for the experiment is the central zone. In terms of constructions it has:

- 23 residential buildings;

- 27 public activities; 
- 44 private activities;

- 1 school.

In terms of users it has:

- 255 residents;

- 212 employers;

- 170 occasional users;

- 159 students and teachers;

- 5 weekly users.

Multi-stage demand models are calibrated and validated (Figure 3). The generation models are separated into residents, workers, occasional customers, teachers and students, weekly users. A model for joint modal split and distribution is defined.

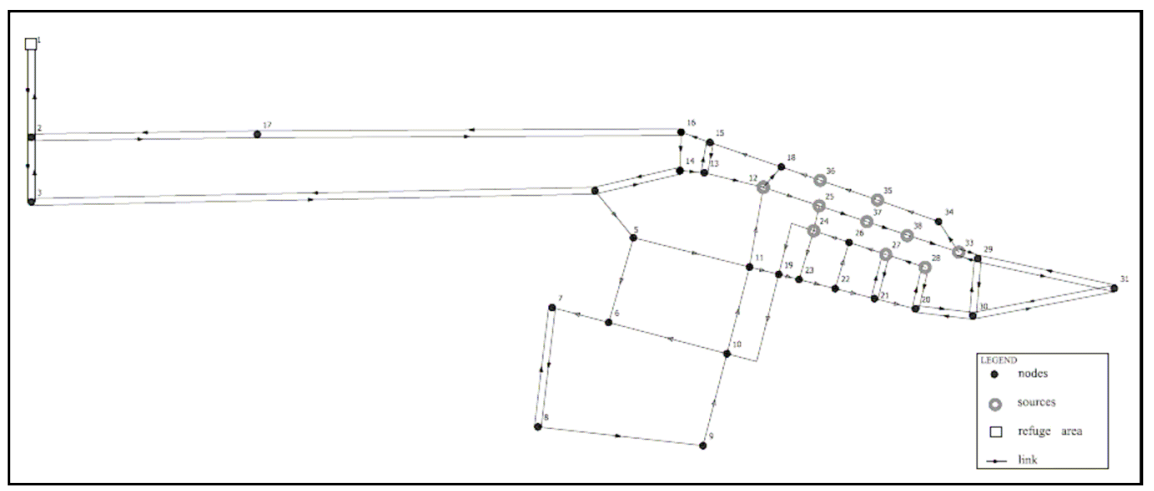

Figure 3: Graph considered for the simulation.

The supply is simulated with a topological approach; the model contains 11 origin zones, 2 assembly points, 21 nodes and 66 links (Figure 4). The main activities concern the calibration of the speed-density function that is used in the supply model. The function derives from car-following theory and is modified to be used for macroscopic, mesoscopic and microscopic supply-demand interaction models. After calibration, the total evacuation time simulated with pseudo-dynamic, mesoscopic and microscopic approaches is very similar to the real evacuation time measured.

The refuge areas are simulated by considering queuing theory. Two problems arise: simulation of the queue in the entry point and simulation of the parking search space. The entry points into the safe area are simulated with deterministic theory for traffic flow. Simulation of the parking search space is performed with a microscopic model with discrete events.

Path design for emergency vehicles is considered separately for the problem of connecting one origin and one destination (called one to one) and the problem of connecting many (or one) origins and one (or many) destination (called many to one). The first problem is termed minimum path in the literature and the second the routing problem. The path followed by emergency vehicles is 
reproduced considering multi-path and multi-criteria generation methodology. Applying the design methodology the total time in a one-to-one approach could be reduced by $15 \%$ and in many-to-one by $20 \%$.

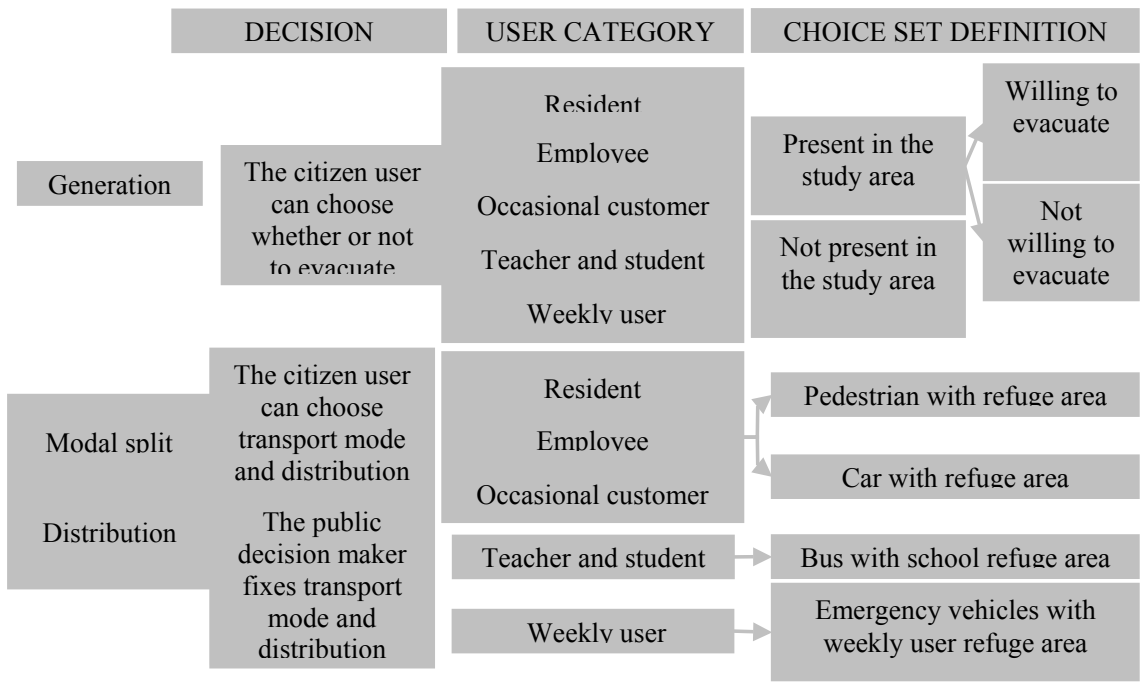

Figure 4: $\quad$ Proposed model structure for the demand.

In the school a mesoscopic model is considered to simulate user pedestrian behaviour. Separate models for the time spent by users in the various components of supply are calibrated. Finally, the guidelines for the planning process are produced. To support the guidelines a prototype laboratory decision support system with all the calibrated models is implemented on Windows and Linux operative systems.

\section{Structure of the papers}

In relation to the six tasks of the project reported in section 4, the results may be viewed in detail in the following papers published in the same proceedings:

- Demand model (by F. Russo, G. Chilà);

- supply and supply-demand interaction models for users (by A. Vitetta, G. Musolino, F. A. Marcianò);

- $\quad$ simulation of refuge area for users (by A. Vitetta, V. Assumma);

- design of path choice models for emergency vehicles (by A. Vitetta, A. Quattrone, A. Polimeni);

- pedestrian outflow models in a building (by M. Di Gangi, P. Velonà);

- planning process and guidelines (by F. Russo, C. Rindone).

All the models calibrated confirm that the simulated results are very similar to the real values. The differences in the values are on average little more than $10 \%$ and in no case are greater than $20 \%$. This is very encouraging since evacuation 
can now be simulated and designed. The design of the same evacuation, considering the calibrated models, could add $20 \%$ time to saving lives.

Research for the analysis and the modelling of transportation systems in emergency conditions requires further studies. There is the need to extend the methodology and rearrange standard procedures. Experimentation in larger areas as well as specification and calibration of what to models has to be developed.

\section{References}

[1] Kindinger, J. P. (2004). Programmatic Risk - Overview of Methods for Decision Making \& Risk Management. Los Alamos National Laboratory document LA-CP-04-0626.

[2] University of Maryland (2005). Fire and Rescue Institute http://www.mfri.org.

[3] Russo, F. (2004). Evacuazione dei sistemi urbani. Franco Angeli.

[4] Goldblat, R. (2004). Evacuation planning. Human factor and traffic engineering perspectives. Proceedings of the European Transport Conference. Strasbourg.

[5] Ben Akiva, M., S. Lerman (1985). Discrete choice analysis: theory and application to travel demand. MIT Press, Cambridge, MA.

[6] Sheffi, Y. (1985). Urban transportation networks. Prentice Hall, Englewood Cliff, NJ.

[7] Train, K. (2003). Discrete choice methods with simulation. MIT Press Cambridge, Massachusetts.

[8] Cascetta, E. (2001). Transportation systems engineering: theory and methods. Kluwer Academic Press.

[9] Lowrance, W. W. (1976). On acceptable risk: science and determination of safety. Los Altos, CA: William Kaufman.

[10] Katzman, G. (2005). Protecting against terrorist attacks for urban transportation projects. Safety and Security Engineering. WIT, 763-772.

[11] Russo, F., A. Vitetta (2006). Risk Evaluation In A Transportation System. International Journal of Sustainable Development and Planning, Vol1, Issue 2. 